\title{
OS FRUTOS DE MAIO: RESENHA HISTÓRICA DO MOVIMENTO ESTUDANTIL NA AMÉRICA LATINA NO INICIO DO SÉCULO XX ${ }^{1}$
}

\author{
José Rubens Lima Jardilino 2 \\ Universidade Nove de Julbo- UNINOVE-Brasil \\ Sociedad de Historia de la Educación Latinoamericana-SHELA. Grupo HISULA \\ jrjardilino@gmail.com
}

Recepción: 30/05/2008

Evaluación 01/06-15/09/2008

Aceptación: 29/09/2008

Artículo de Reflexión

\section{RESUMEN}

En este artículo me propongo examinar las cuestiones de la historia social de los movimientos estudiantiles en el continente, tomando como caso de Argentina, Perú, Cuba y México, por supuesto lo hago en plena colaboración con los especialistas con los cuales mantengo diálogo intenso y los tengo como referencia de mi narrativa sobre el tema. Los movimientos estudiantiles reciben diferentes interpretaciones de su protagonismo juvenil. En Francia, incluso con los socialistas en el poder, hubo un trabajo de la

1 Texto apresentado no seminário temático do programa de Pós-graduação Mestrado e Doutorado em Educação da Universidade Nove de Julho, realizado em São Paulo, 15 de Maio de 2008

2 É licenciado em Filosofia pela Faculdade Associadas Ipiranga (1995),possui graduação em Teologia pela Faculdade Teológica de São Paulo (1986), mestrado em Ciências da Religião - com concentração na área de Sociologia da Religião - pela Universidade Metodista de São Paulo (1993) e doutor em Ciências Sociais pela Pontifícia Universidade Católica de São Paulo (1997). Realizou estudos de Pósdoutoramento em Ciências da Educação na Université Laval, Québec, Canadá(2007) e na Universidad Pedagógica y Tecnológica de Colombia (UPTC). É professor titular do Departamento de Educação da Universidade Nove de Julho - UNINOVE, atuando no PPGE/Uninove desde sua fundação, pesquisando e orientando nas linhas de História da Educação e Formação de Professor. Atualmente é pesquisador e professor convidado do Programa de Doutorado em Ciencias de Educação de REDECOLOMBIA, da Universidade Pedagógica y Tecnológica de Colômbia e da Universidade Pablo de Olavid en Sevilla, España. É Editor da Eccos Revista Científica. Membro da Sociedad de Historia de la Educación Latinoamericana SHELA, e atualmente preside a sociedade (2008-2011) 
desfiguración del movimiento poco después de su término. Mayo del 68 fue establecido definitivamente como una revuelta de la juventud, o como la juventud es considerada el tiempo del amor y pasiones, el movimiento de 1968, se asimila como una aspiración de los jóvenes en la búsqueda de suprimir el yugo de los padres y de los tabúes sexuales. Por otra parte, hay que reconocer en el movimiento francés sus fuertes contenidos culturales y su firme deseo de cambiar las estructuras institucionales de la modernidad la Universidad, la Familia, señalando como un movimiento social que se solidarizan a asociaciones como de los agricultores y de los trabajadores en general en la lucha por un cambio cultura. También hay quienes afirman que su legado ha dejado sólo el peso de la droga a un mundo postmoderno y esotérico. En frente de esta diversidad de visiones, nosotros tomamos la libertad de entender el movimiento de los 68 en una perspectiva histórica del papel de los jóvenes en búsqueda de los cambios en las estructuras sociales, desde principios de siglo.

Palabras-clave: Movimiento estudiantil; movimientos sociales; cambios sociales

\title{
THE FRUIT OF MAY: HISTORIC REVIEW OF STUDENT MOVEMENT IN LATIN AMERICA IN THE BEGINNING OF THE TWENTIETH CENTURY
}

\author{
José Rubens Lima Jardilino \\ Universidade Nove de Julho - UNINOV E- Brasil \\ Sociedad de Historia de la Educación Latinoamericana-SHELA. Grupo HISULA \\ jrjardilino@gmail.com
}

\begin{abstract}
In this article, I intend to review the issues of social history of student movements on the continent, focusing on Argentina, Peru, Cuba and Mexico. Of course, I do it in full partnership with specialists with whom I maintain intensive dialogue about my narrative on the subject. In France, even with the Socialists in power, there was a defacement work of the movement soon after its end. May 68 was definitively established as youth's revolt or youth's love time. The movement of 1968 was like an aspiration of young people seeking to abolish the father's yoke and sexual taboos. Moreover, we must recognize the French cultural content movement and its strong
\end{abstract}


desire to change the institutional structures of modernity - University, family, pointing it as a social movement that align strong partnerships between farmers and workers in the fight for a culture change. There are also some who say that its legacy has left only the weight of drugs to a postmodern and esoteric world. In front of this diversity of visions, we take the freedom to understand the movement of "half-eight" in a historical perspective of the role of youth, who claimed changes in social structures since the beginning of the century.

Keywords: Student Movement, social movements, social change.

\section{INTRODUÇÃO}

O tema deste texto, que por sinal de veio poético, junto com uma miríade de publicações, reportagens e eventos para celebrar, ou melhor, rememorar os 40 anos dos "meia-oito 3" nos leva, hoje afastados da euforia sócio-político que os motivara, a uma análise mais distanciada e às vezes também equivocada. Tudo depende do lugar do qual estamos falando. Jaccques Rancière aponta que na França mesmo com os socialistas no poder, houve um trabalho de desfiguração do movimento logo após seu termino. "Maio de 68 foi definitivamente consagrado como uma revolta da juventude. A juventude é tida como o tempo dos amores e o movimento de 1968, foi assimilado como uma aspiração dos jovens a abolir o jugo paterno e os tabus sexuais" 4 . Maria da Glória Gohn ${ }^{5}$ por outro lado, embora reconheça no movimento francês seu forte conteúdo cultural e o desejo de mudanças das estruturas institucionais da modernidade - a Universidade, a Familia, ela aponta que foi um movimento com um acento social forte ao aliar-se aos camponeses e operários na luta por uma mudança cultural. Também a quem diga que seu legado deixou apenas o peso das drogas para um mundo pósmoderno e esotérico.

$\mathrm{Na}$ verdade esse preâmbulo nos permite colocar o movimento dos “meia-oito" na perspectiva histórica do protagonismo da juventude que reivindicava as mudanças nas estruturas sociais, desde o inicio de século, possivelmente não tão "providencialmente" como expressou Carlos Fuentes ${ }^{6}$

3 Essa expressão é um neologismo e tem pouca significação para os hispanoshablantes, por isso aqui tentamos traduzir seu significado figurado. O numeral 6 em português no Brasil geralmente é chamado de "meia" (la mitad de la docena "12"). Por isso designamos de "meia-oito".

${ }^{4}$ Reportagem do caderno comemorativo dos 40 anos do maio de 68. in, Cadernos Mais. Jornal Folha de São Paulo de 04 de maio de 2008

5 Ibiden

${ }^{6}$ Los 68: Paris-Praga-México. Debate: Mexico, DF, 2005. 
"o 68 foi, por princípio, um destes "anos-constelação" que sem a menor racionalidade explicável, coincidem fatos, movimentos y reúne personalidades inesperadas e separadas em diferentes espaço ${ }^{7 "}$. Os Vintecentistas já analisam esses movimentos numa rede que ao longo da primeira metade, vai se configurando numa ruptura com a sociedade patriarcal e autoritária que nos legou o século XIX. É nesta perspectiva que ousei denominar como os frutos de maio o movimento de 68 oriundos daqueles movimentos que no inicio do século tiveram como pauta de suas lutas as reformas na sociedade Latino-americana. Esses são como as flores que vão se constituir em frutos primévos, germinados no 68 europeu.

Para realizar tal exercício, dialogo nessa conversa com alguns amigos 8 latino-americanos com os quais tenho aprendido muito sobre o movimento estudantil e as respectivas reformas da universidade, bandeira primeira das reivindicações, das quais esses foram articuladores.

Devo esclarecer que não sou especialista na temática, tenho acompanhado o debate em torno dos movimentos estudantis na América Latina, por meio de simpósio e debates promovidos pela Sociedad de História de la Educación Latinoamericana - SHELA ${ }^{9}$, em especial, com os relatórios do Grupo HISULA - Historia de la Univerisdad Latinoamericana apresentados em congressos sobre Historia das Universidades em América y Europa ${ }^{10}$, realizados em vários países da Latino América, conforme nota acima. Dadas as devidas explicações, Me proponho apenas resenhar as questões da história social desse movimento no continente, naturalmente em plena parceria com os especialistas aqui já mencionados.

7 Ibdem, p.11 tradução livre do autor do original: "El 68, por principio de cuentas, es uno de esos años-constelación en los que sin razón inmediatamente explicables coinciden hechos, movimientos y personalidades inesperadas y separadas en el espacio". 8 MARSISKE, Renate. Movimientos estudiantiles en América latina: Argentina, Perú, Cuba y México - 1919- 1929.; VARGAS HENANDEZ, Olmedo. (2005): Movimientos Universitarios: América Latina, siglo XX.; ACEVEDO TARAZONA, Álvaro. Modernización, conflicto y violencia en la universidad en Colombia.; VERA FLASCH, María Cristina. Reformas y contrarreformas en la Universidad de Córdoba, 1918-1936. y, em especial no Brasil, meu colega e companheiro de equipe de pesquisa Carlos Bauer

${ }^{9}$ Tanto nos simpósio coordenados por mim e por Dra Diana Soto nos congressos de Americanistas, como nos próprios congresso de SHELA, realizados: 1992 em Bogotá; 1994 em Campinas, UNICAMP, Brasil; 1996 em Caracas, Venezuela; 1998, em Santiago de Chile; em 2002, Piura, Peru e o ultimo realizado em Guadalajara, México em 2007. Obs. O próximo est;a agendado para agosto de 2009 em São Paulo, Brasil.

10 Foram realizados VI congresso, respectivamente, em Córdoba, Argentina (Univerdiade Nacional de Córdoba, 2003; em Cartagena, Universidad de Cartagena, 2004; León, Espanha, Universidad de León, 2005; em Barquisimeto, Venezuela Universidad de Thátira, 2006; Em Victória de Tamaulipas, México (Universidad de Tamaulipas, 2007 e em Tunja, Colômbia, Simpósio dentro do XIV Congreso Colombiano de História.UPTC, Tunja, Colômbia. 


\section{Os antecedentes do movimento cultural e reformador de 1968.}

\subsection{Córdoba: a semente que germinou e deu muitos frutos}

A movimentação dos estudantes por participação na vida universitária remonta o final do século XIX. Havia não somente na Argentina, mais também no México, o desejo dos jovens de se tornarem sujeitos ativos do processo social. Esse protagonismo juvenil universitário se acelera e se materializa em contestação aos modelos de ensino, ao currículo e a própria política universitária, inspirados pelas novas correntes de pensamento do inicio do século XX e herdeiros de uma classe média em ascensão.

$\mathrm{Na}$ América Latina no inicio do século XX o crescimento populacional, sua acelerada urbanização com necessidades de criar a infra-estrutura para dar condições ao modelo exportador de economia e a respectiva industrialização da sociedade, repercutiram fortemente na classe média que tomava formato em vários países. Em alguns deles como Argentina, Brasil, México entre outros, o sistema concentrado do poder econômico, político e cultural dificultou no século anterior a formação dessas novas elites, as quais nasciam sob as luzes das idéias do novo século e começavam a formar setores médios que ganhavam importância em todos os setores da cena nacional. Junta-se a esse fator os grupos de trabalhadores, conseqüência do processo imigratório que começa a se organizar, os pequenos comerciantes, trabalhadores do campo e do setor de serviços com a gama de bacharéis e profissionais liberais que emergiam nesse contexto, Todos lutavam por encontrar um lugar na cena política e social de uma sociedade em profundas rupturas. É neste contexto que podemos falar do protagonísmo dos estudantes.

Conforme Victória Kandel ${ }^{11}$. As primeiras idéias que impulsionaram a luta pela representação política dos estudantes no governo universitário tiveram como berço Buenos Aires (UBA) e Montevidéu com o Primeiro Congresso de Estudantes Americanos, realizado nos dias 26 de janeiro a 8 de fevereiro de 1908. O congresso, embalado pelo Pan-americanismo da época se realizou em torno do ideal de Reforma na Universidade e sua principal motivação era a representatividade dos estudantes nos conselhos

11 KANDAL, Victoria. (2006): Los estudiantes y su inclusión en el gobierno universitario - una historia con vaivenes en la Argentina del siglo XX. In., Movimientos estudiantiles en América y Europa. VERA de FLASCH, Maria Cristina (ed), Córdoba, Junta Provincial de História de Córdoba, Córdoba, Argentina, pp. 149-174. 
diretivos das universidades, como apresenta uma das declarações publicadas 12 logo após o evento.

"El Primer Congreso Internacional de Estudiantes Americanos nos acepta como una aspiración, que es de desearse sea llevada pronta a la práctica, la representación de los estudiantes en los Consejos Directivos de enseñaza universitaria, por medio de delegados, nombrados directamente por ellos y renovados con la mayor frecuencias posible"

As universidades latino-americanas estavam longe de responder o que os países necessitavam para seu desenvolvimento frente à urgência de mudanças nas arcaicas instituições sociais dos séculos anteriores. "La orientación de la enseñaza universitaria era profesional y utilitaria, la universidad era productora de ciertas profesiones liberales, como juristas, médicos, ingenieros y arquitectos, quienes estabas destinados a servir las clases altas en campos bien definidos. En el contexto de una cultura fundamentalmente acientífica y técnica, las escasas o insuficientes actividades de docentes y de investigación, que se cumplen en las universidades, lo hacen bajo el signo de las orientaciones que enfatizan la memorización y la erudición sin sentido, el razonamiento observado, el escolasticismo y el dogmatismo, la subordinación de las ciencias físico-naturales y sociales a la filosofía e a la ideología oficiales, el divorcio de la práctica, la limitación servil y la repetición formal y pasiva de todos lo que viene desde afuera"13

Argentina, no cone sul, por seu desenvolvimento no inicio do século se transforma no lugar símbolo de atuação dos estudantes em busca de mudanças e de adequação de suas estruturas sociais ao novo mundo. $\mathrm{O}$ congresso de Montevidéu foi o detonador da organização dos estudantes latino-americanos a começar pela Argentina na emblemática movimentação estudantil de Córdoba em 1918, da qual muitos outros frutos se espalharam por todo o continente.

Em março de 18, depois das greves realizadas no ano anterior, as faculdades de engenharia e medicina reivindicavam a reforma do sistema vigente para a provisão de cátedras y a pronta revogação da suspensão do internato dos estudantes avançados na carreira de medicina no Hospital das Clínicas, no que não foram atendidos. Diante do fato, organizaram o primeiro comitê Pró-Reforma que convocou a greve geral da universidade

12 Esta declaração consta das fontes de pesquisa de Del Mazo, G. Estudiantes y Gobernos Universitários. Universidad Nacional de San Luis Argentina apud. Kandel (2003:152).

13 MARSISKE, Renate. (2003): Movimientos Estudiantiles en América Latina: Argentina, Perú, Cuba y México - 1918-1929. CESU \UNAM, México, p.22) 
de Córdoba. Dizia o manifesto: "Nos levantamos para sacudir a escravidão mental sob a qual nos matem; para romper o circulo vicioso da anacrônica cátedra (Maestranza) que nos aprisiona nos horizontes da luz espiritual; para arrancar a carga monstruosa e torturante que a inércia docente nos impõe como bagagem inútil para o nobre exercício das profissões liberais".

O comitê estruturado solicitava a intervenção da universidade e apresentava sua bandeira: democratização da universidade, renovação do professorado, reforma do currículo, periodicidade de cátedra para sua renovação e atualização e, por fim, concursos públicos para a provisão de cargos. A vitória política dos estudantes fez o presidente H Irygoyen nomear um interventor na Universidade de Córdoba, José Matienzo simpatizante do movimento dos estudantes que realizou uma Reforma (de Matienzo) incluindo os estudantes no governo da universidade e atendendo boa parte de suas reivindicações.

O Comitê de Reforma se converte em Federação Universitária de Córdoba e edita um jornal chamado Gazeta Universitária. Todavia, os conflitos políticos se seguiram quando da eleição de novo reitor, se reacende a disputa entre a oligarquia cordobesa e os estudantes. Isso leva à novos interventores e culmina com a nomeação de um ministro para instrução pública, mas os acirramentos dos conflitos mantêm por um tempo a Universidade fechada. Quando em 9 de setembro a Federação decide abrir a universidade tomando o poder temporário, nomeia suas autoridades e normaliza as atividades de aulas. Os três decanos (Faculdades de Medicina, Engenharia e Direito) exerceriam conjuntamente o governo da universidade e chegam a nomear novos professores e pessoal administrativo. Ato simbólico que durou pouco, o ministro de Instrução Pública intervém no conflito, pede a renuncia de todos, nomeando novos catedráticos e, por fim promove uma reforma dos estatutos na qual inclui as principais propostas dos estudantes (docência livre e participação dos estudantes no governo da universidade).

O movimento de reforma universitária em Córdoba conseguiu:

1. Eleição dos dirigentes pela própria comunidade universitária constituído pelo colegiado de professores, egressos e estudantes.

2. Concursos para a seleção de professores e Cátedras com períodos determinados.

3. Liberdade de Docência e liberdade de assistência as aulas

4. Modernização dos métodos de ensino

5. Assistência Social aos estudantes e a democratização de ingresso na universidade. 
Todas essas reformas foram estendidas ao sistema universitário argentino. Pode-se dizer que o movimento de Córdoba foi, não somente uma confrontação a sociedade arcaica e o reduto colonialista argentino, mas representou uma proposta de mudança na estrutura universitária em toda América Latina. Como se refere Marsiske:

"Como la revolución de la Independencia frente al colonialismo español, como el modernismo frente a residuos culturales de ese coloniaje, la Reforma Universitaria se alimenta de aprestos de contemporaneidad (...) Los estudiantes reformistas combatieron la influencia de la Iglesia Católica en la Universidad. Querian reemplazar el catolicismo por el positivismo cientifico y el liberalismo económico. Además, sabian que podian contar con el apoyo de las nuevas clases medias y del proletariado mientras mantenían su anticlericalismo, ya que el catolicismo era la ideología de las oligarquías, que controlaba todos los aspectos de la vida cordobesa e impedía en la universidad una enseñaza acorde al tiempo. Decian los estudiantes: Hombres de una república libre, acabamos de romper la ultima cadena que, en pleno siglo XX, nos ataba a la antigua dominación monárquica y monástica, In., Manifiesto - La juventud Argentina de Córdoba a los hombres libres de Sudamérica 14 ",

\section{Peru e Cuba movimento estudantil e as reformas populares}

Como já dissemos acima o movimento de Córdoba atuou em efeito domino. Todavia não se pode dizer que os estudantes dos países que foram animados pelas lutas e conquistas de Córdoba apenas o tenham imitado. $\mathrm{Na}$ verdade Córdoba serviu como inspiração e não como modelo. A explicação que se pode dar é que, por trás dessa continentalidade que o movimento dos estudantes expressou, no que pese a diversidade cultural particular de cada país, encontramos as mesmas estruturas de sociedade. A América Latina dominada por espanhóis e portugueses que usaram as mesmas estratégias de dominação por séculos. As mesmas estruturas dominantes se expressam tanto no cone sul como na Meso-América, portanto é natural que haja semelha nos ideais em conquistar maior participação social e política nesse movimento latino-americano de renovação das estruturas, uma vez que os vastos setores sociais estavam sobre o mesmo signo de mudanças no inicio do século, uns mais a frente, outros com maiores dificuldades.

14 MARSISKE, Renate. (2003): Movimientos Estudiantiles en América Latina: Argentina, Perú, Cuba y México - 1918-1929. CESU \UNAM, México, pp. 22 y 34. 
As duas expressões do movimento estudantil por reforma que eclodiram no Peru e em Cuba tiveram um caráter mais popular, pelo seu alto grau de politização eles lutaram por uma reforma acadêmica e uma renovação social. Era mais que um movimento estudantil, era um movimento social com matizes política mais definida.

"Desde 1923, los estudiantes de la Reforma se filiaron a las cuatro tendencias politicas dominantes: la libertadora que tenía la idea de una transformación social definitiva do país; la conservadora, refugio de la oligarquia aristocratizante; la Alianza Popular Revolucionaria-APR A creada por Victor Raúl Haya de la Torre, dirigente estudiantil que expresó el pensamiento avanzado de entonces, y en menor grado, la corriente marxista, representada por José Carlos Mariátegui, quien supo adecuar el pensamiento de Kart Marx a la realidad peruana 15 ",

Ora mesmo que vejamos essa distinção nos movimentos, os estudantes de Peru e Cuba também faziam parte de uma classe media emergente. Todavia deve-se ressaltar que estes eram oriundos de filhos da aristocracia regional empobrecida pelo capital estrangeiro de modelo agro exportador e frutos de um processo a migração interna em busca de trabalho no setor de serviços. Essa é a composição da nova classe media urbana do Peru e os estudantes de 1919 fazem parte dela. A luta por livre assistência as aulas, diferentemente de Córdoba, se dava por necessidade de ajuste de horário, uma vez que a maioria deles tinha que trabalhar para manter seus estudos e não podiam, portanto, se adaptar aos horários estabelecidos. Como bem acentuou Portantiero, J. Carlos: "Dentro de una sociedad dependiente, con un proletariado escaso y sin tradición organizativa autónoma y con una burguesía industrial virtualmente inexistente, no es extraño que dado un proceso de movilización de las clases medias, el papel de vanguardia para una agitación política y social caiga en poder del estudiante universitario 16 ".

Tal como Córdoba, houve intervenções, greves e os ânimos dos estudantes se arrefeceram por uma querela docente entre um professor de história e um estudante da faculdade de Letras e Humanidades que formou o rastilho de pólvora da Reforma Universitária Peruana, em especial na medieval Universidad de San Marcos. Assim que em 4 de setembro de 1919 os estudantes em greve frente ao Palácio do Governo exigiam a extinção da lista de presença, a representação estudantil no conselho universitário e a renúncia dos professores medíocres - Cátedra livre. O movimento ganhou cores políticas fortes. Augusto Leguía utilizou-se das demandas estudantil e

15 MARSISKE, op.cit., p. 36.

16 MARSISKE, Ibidem, p. 36. 
começou a Reforma com o intuito de expulsar seus inimigos políticos na Universidade. Com isso encampou todas as reivindicações num decreto de 20.09.1919 estabelecendo Cátedras livres, Representação estudantil no CU e suspensão das listas de presença. Depois promulgou as leis da reforma 4002, 4004 que incluía a autonomia da Universidad de San Marcos.

Diante de tal sucesso os estudantes sobre a liderança de Victor Raúl Haya de la Torre se lançaram num movimento de reformas sociais. O congresso de estudantes de 1920, além das discussões sobre o andamento da Reforma, teve como principal decisão criar a Universidade Popular, inaugurada em 22.01.21 com o slogan 'la universidad popular no tiene más dogma que la justicia social'. Esse modelo de universidade se espalhou pelo país até 1924, que por decisão do governo foram fechadas, permanecendo somente a de Lima.

Em conclusão podemos dizer que as conquistas mais importantes da Reforma Universitária peruana foram: autonomia universitária, cogovernabilidade e extensão universitária por meio da universidade popular. Assim a referida reforma foi bem mais que um simples caso entre estudantes e alunos, como muitos querem indicar, mas abriu um debate político no continente, especialmente pela figura de seus dois líderes Haya de la Torre e J.C. Mariátegui, os quais orientaram o movimento para se desenvolver na formação de partidos políticos para as classes medias e populares.

Em Cuba, também, para mais além de uma Reforma Universitária, a exigência de autonomia ampla, os estudantes buscam uma autonomia política, administrativa e econômica. De semelhante forma, buscam uma Reforma do Estado e por isso a preocupação e mais com o popular, por isso mesmo criam a Univerisdad Popular José Martí que foi uma ferramenta na aproximação dos estudantes com os trabalhadores. Os líderes do movimento estudantil cubanos estavam próximos do La Torre. Quando da criação da UPJM, seu primeiro artigo no estatuto dizia: A Classe operária cubana funda, professa e dirige a Universidade Popular José Marti. Era gratuita sem taxa alguma, aberta a todas as classes sociais e funcionava com livre participação de professores e alunos. Não outorgava títulos nem tinha regime de notas.

Os estudantes tiveram poder e autonomia ainda que com muita luta, em fim. O nacionalismo democrático martiano sua vinculação com as tradições socialistas, a aproximação entre as classes medias e os setores populares que cristalizou a Reforma Universitária e o peso da juventude como elemento dinamizador da atividade política para o resta da sociedade, põe um acento demasiadamente político no movimento estudantil cubano. Há mesmo quem chega a pensar na idéia de continuidade desse movimento com a Revolução Cubana e o castrismo posterior. 
Pero lo notable de esta continuidad, cuando la asume el castrismo, es que se revela como una sintesis ideológica y práctica de cuarenta años de enfrentamiento interno en el movimiento de las juventudes universitarias como el resumen superador de una doble perspectiva de la bistoria politica del continente... 17

\section{México: O movimento estudantil dentro da Revolução: uma contra-revolução?}

Como apontamos nos casos acima tratados, o surgimento das classes médias como novos sujeitos sociais, jogam um papel importante na cena latino-americana onde eclodiram os movimentos estudantis e as respectivas reformas sócias empreendidas. Frutos da modernização, que foi a matriz decisiva para a industrialização, e as democracias dos estados latinos antevistas desde os movimentos de independência, elas (classes médias) se constituíram como representantes do povo contra as velhas oligarquias que, a sua moda, impendia a construção de um estado democrático. O movimento estudantil do século XX é herdeiro direto dessa classe insurgente. O descontentamento e a falta de organização da sociedade civil, ainda sob as sobras do ancien regime, canalizam suas reivindicações de uma nova sociedade por meio dos movimentos nas universidades. Daí a importância dessas sementes que nos fazem hoje sob outro contexto relembrar outro movimento, o dos meia-oito.

Diferentemente dos países do cone sul, o México nos tempos pósrevolucionários esteve desatento às classes médias como afirma Marsiske (2005) Os filhos das novas classes médias, resultado da política de expansão econômica do regime de Porfírio e das mudanças provocadas pela revolução, se sentiam excluídos da estrutura social e universitária e reclamavam um lugar ao sol. A universidade nacional do México esteve desde sua criação em crises, fechada em 1865 foi somente recriada em 1910, pouco tempo depois da vitória da revolução. Mesmo assim a educação superior era elitista e a universidade dependia do clima político no vai-e-vem das disputas revolucionárias e dos projetos educacionais de cada governo. É neste contexto que o podemos distinguir as lutas dos movimentos de estudante do México em relação aos do cone sul.

El movimiento estudiantil de 1929 puso en el centro de la discusión el futuro de una institución que necesitaba una urgente reforma internay un cambio en su relación con el gobierno. Estaba en juego el futuro de los bijos de las clases medias en un país que estaba dedicado a construir las bases institucionales para la integración de la nación mexicana favoreciendo las clases populares, pilares de la revolución.

17 MARSISKE, Portantiero, op.cit. 
Será que podemos falar de do movimento estudantil do México como uma contra-revolução. Os estudantes que estiveram à margem do movimento revolucionário são chamados em 29 para reconstruir o projeto político e reacende o fervor e o ideário da revolução, com objetivo de reconstrução social e renovação da ética. Entretanto, por variados fatores políticos a nova lei orgânica da Universidad Nacional de México, Autônoma escapou aos intentos do movimento. Depois de um percurso de muita luta e embate político o presidente de então Emílio Portes Gil, com interesse em terminar com o conflito por medo de uso político por seu adversário, ofereceu um solução pacificadora - a promulgação de uma nova lei Orgânica para a Universidade definindo suas funções de docência, pesquisa e extensão, além de outorgar a autonomia da Universidade. "Finalmente el 10 de julio de 1929, fue promulgada la Ley Orgánica de la Universidad Nacional Autónoma de México. Como apontou Marsiske18 "En los considerandos de la ley se reflejó toda la ideología del estado mexicano posrevolucionario y sus ideas operantes sobre la educación y la universidad, en especial".

A lei orgânica da Universidade arrematava: "Que es un propósito de los gobiernos posrevolucionarios la creación de instituciones democráticas funcionales que debidamente solidarizadas con los principios y los ideales nacionales y asumiendo responsabilidad ante el pueblo, quedan investidas de atribuciones suficientes para el descargo de la función social que les corresponde"

\section{CONSIDERAÇÕES FINAIS}

Naturalmente, se pode pensar nos movimentos de estudantes da primeira metade do século XX como o embrião de uma mudança de mentalidade político e social do continente latino-americano. Eles não podem ser considerados apenas como esforços estreitamente ligados a questões do métier da Universidade, mas é para além das reformas educacionais que suas lutas promoveram, refletiam as demandas de seu tempo, o surgimento de uma classe média que tinha como pressuposto básico a construção política e a Reforma do Estado. As Reformas das instituições do Estado, entre elas a Universidade de certa maneira adaptaram a sociedade latino-americana para as exigências do novo século. Existia nesses movimentos uma estreita relação entre projeto educacional de ensino superior e governo; universidade e sociedade; movimento estudantil, desenvolvimento e insurgência das classes média na América Latina, como novo protagonista da ação político-social.

Por mais burguesa que tenha sido o movimento em Córdoba, ele lançou as bases para as matrizes político-social dos movimentos do Peru, Cuba e para o re-arranjo do ideal revolucionário da juventude mexicana.

18 MARSISKE, Renate. (2003): Movimientos Estudiantiles en América Latina: Argentina, Perú, Cuba y México - 1918-1929. CESU\UNAM, México, p.22. p.34). 
Quaisquer que sejam as motivações da Reforma Universitária, empenhada pelos movimentos de estudantes de cada país, podemos dizer que eles simbolicamente representam as flores que germinaram e se transformaram nos frutos colhidos de maio de 1968. Termino com uma frase emblemática do manifesto de comitê pró-reforma de Córdoba.

Hemos resuelto llamar todas las cosas por el nombre que tienen. Córdoba se redime. Desde hoy contamos para el país una vergüenza menos y una libertad más. Los dolores que quedan son las libertades que faltan. Creemos no equivocarnos, las resonancias del corazón nos advierten: estamos pisando sobre una revolución, estamos viviendo una hora americana.

\section{FUENTES}

ARCHIVO

Reportagem do caderno comemorativo dos 40 anos do maio de 68. in, Cadernos Mais. Jornal Folha de São Paulo de 04 de maio de 2008

DEBATE:

Los 68: París-Praga-México, México, DF, 2005

ORGANIZACIÓN DE EVENTOS:

Simposio coordenados por mim e por Dra Diana Soto nos congressos de Americanistas, como nos próprios congresso de SHELA, realizados: 1992 em Bogotá; 1994 em Campinas, UNICAMP, Brasil; 1996 em Caracas, Venezuela; 1998, em Santiago de Chile; em 2002, Piura

VI Congresso, respectivamente, em Córdoba, Argentina (Univerdiade Nacional de Córdoba, 2003; em Cartagena, Universidad de Cartagena, 2004; León, Espanha, Universidad de León, 2005; em Barquisimeto, Venezuela Universidad de Thátira, 2006; Em Victória de Tamaulipas, México (Universidad de Tamaulipas, 2007 e em Tunja, Colômbia, Simpósio dentro do XIV Congreso Colombiano de História.UPTC, Tunja, Colômbia

\section{SELECCIÓN BIBLIOGRÁFICA}

ACEVEDO TARAZONA. Álvaro, Modernización, conflicto y violencia en la universidad en Colombia: AUDESA 1953-1984.

FUENTES, Carlos. (2005): Los 68: París-Praga-México. Debates, México.

JARDILINO, J.R.L. (2006): El tema de la autonomía em las Reforma Educativas em América Latina. In., VERA de FLASCH, María Cristina (ed) Movimientos estudiantiles en América y Europa. Córdoba, Junta Provincial de História de Córdoba, Córdoba, Argentina. 
JARDILINO, J.R.L. (2006): Autonomía amenzada: las políticas orientadoras de las reformas educativas em América Latina. In., LAFUENTE, María Isabel. ¿'Hacia dónde vá la educación universitaria americana y europea? Historia, temas y problemas de la universidad. Universidad de León, León España.

KANDAL, Victoria. (2006): Los estudiantes y su inclusión en el gobierno universitario - una bistoria con vaivenes en la Argentina del siglo XX. In., VERA de FLASCH, María Cristina (ed) Movimientos estudiantiles en América y Europa. Córdoba, Junta Provincial de Historia de Córdoba, Córdoba, Argentina.

MARSISKE, Renata. (2005): Clases medias y educación universitaria en América Latina: Argentina y México. In., VARGAS HERNANDEZ, Olmedo. Movimientos Universitarios. América latina siglo XX. RUDECOLOMBIA, Tunja, Colombia.

MARSISKE, Renata. (2003): Movimientos Estudiantiles en América Latina: Argentina, Perú, Cuba y México - 1918-1929. CESU \UNAM, México.

PUYANA MUTIS, Aura María. (2005): Vigencia y Caducidad del movimiento de Córdoba: 1918-1999. In., VARGAS HERNÁNDEZ, Olmedo. Movimientos Universitarios. América Latina. Siglo XX. RUDECOLOMBIA, Tunja, Colombia.

VARGAS HERNÁNDEZ, Olmedo. (2005): Movimientos Universitarios. América Latina. Siglo XX. RUDECOLOMBIA, Tunja, Colombia.

VERA de FLASCH, María Cristina. (2005): Reformas y Contrareformas em América Latina: Argentina y México. In., VARGAS HERNÁNDEZ, Olmedo. Movimientos Universitarios. América Latina. Siglo XX. RUDECOLOMBIA, Tunja, Colombia.

VERA de FLASCH, María Cristina. (2006) (ed): Movimientos estudiantiles en América y Europa. Córdoba, Junta Provincial de Historia de Córdoba, Córdoba, Argentina.

VERA DE FLASCH, María Cristina. (2006): Un precedente de la Reforma del 18: el congreso internacional de estudiantes americanos de 1908. In., VERA de FLASCH, María Cristina (ed) Movimientos estudiantiles en América y Europa. Córdoba, Junta Provincial de Historia de Córdoba, Córdoba, Argentina.

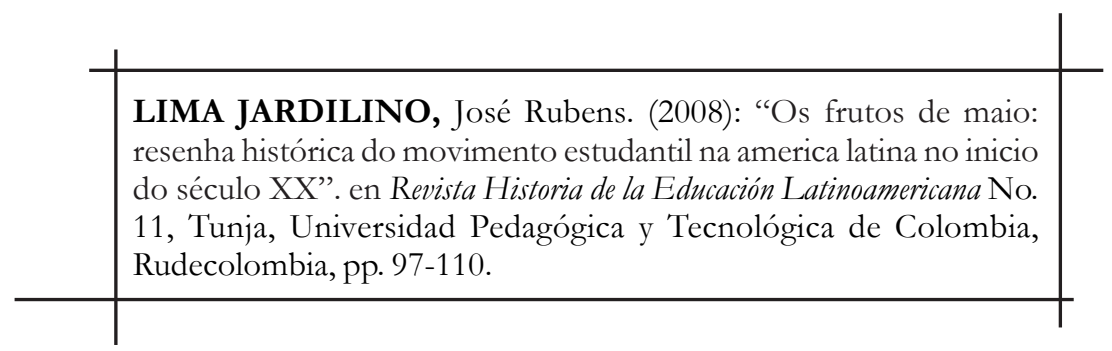

